\title{
PANDORA - Survey of Brazilian Cardiologists about Cholesterol Reduction
}

\author{
Raul D. Santos, Andrei C. Spósito, José Ernesto dos Santos, Francisco H. Fonseca, Emílio H. \\ Moriguchi, Tania L. R. Martinez, Dikran Armaganijam, Sérgio Timerman, Ari Timerman, \\ José C. Nicolau, José A. F. Ramires
}

São Paulo, SP - Brazil

\begin{abstract}
Objective - To report about a group of physicians' understanding of the recommendations of the II Brazilian Guidelines Conference on Dyslipidemias, and about the state of the art of primary and secondary prevention of atherosclerosis.
\end{abstract}

Methods - Through the use of a questionnaire on dyslipidemia, atherosclerosis prevention, and recommendations for lipid targets established by the II Brazilian Guidelines Conference on Dyslipidemias, 746 physicians, $98 \%$ cardiologists, were evaluated.

Results - Eighty-seven percent of the respondents stated that the treatment of dyslipidemia changes the natural history of coronary disease. Although most of the participants followed the total cholesterol recommendations $(<200 \mathrm{mg} / \mathrm{dL}$ for atherosclerosis prevention), only $55.8 \%$ would adopt the target of $L D L-C<100 \mathrm{mg} / \mathrm{dL}$ for secondary prevention. Between 30.5 and $36.7 \%$ answered, in different questions, that the recommended level for HDL-C should be $<35 \mathrm{mg} / \mathrm{dL}$. Only $32.7 \%$ would treat their patients indefinitely with lipidlowering drugs. If the drug treatment did not reach the proposed target, only $35.5 \%$ would increase the dosage, and $29.4 \%$ would change the medication. Participants did not know the targets proposed for diabetics.

Conclusion - Although the participating physicians valued the role played by lipids in the prevention of atherosclerosis, serious deficiencies exist in their knowledge of the recommendations given during the II Brazilian Guidelines Conference on Dyslipidemias.

Kewwords: Hypercaulesterolomia atherosclerosis, risk factors

Department of Atherosclerosis, Department of Clinical Cardiology, and FUNCOR - Brazilian Society of Cardiology

Mailing address: Raul D. Santos - InCor - Av. Dr. Enéas C. Aguiar , 44 - 1o andar - 05403-000 - São Paulo, SP - Brazil - E-mail- rdsf@uol.com.br
In Brazil, according to death certificate data from the SUS (Unified Health System) (Internet site: http//www.saude.gov.br), acute myocardial infarction was responsible for 76.5 $\%(\mathrm{~N}=73,636)$ of deaths second to ischemic heart disease. That represents roughly $15 \%$ of all cause mortality for all ages.

The role played by dyslipidemia in the genesis of coronary atherosclerosis is well established. More specifically, high levels of total cholesterol and LDL-cholesterol (LDLC), reduction in HDL-cholesterol (HDL-C) and increase in triglyceride levels predispose to coronary disease ${ }^{1}$.

Today, the role of hypolipemic therapy in the prevention of coronary artery disease morbidity and mortality is no longer discussed $^{2}$. In 1996, when the results of the secondary prevention study $4 \mathrm{~S}^{3}$ and the primary prevention study WOS$\mathrm{COPS}^{4}$ became known, the findings of the II Brazilian Guidelines Conference on Dyslipidemias were published ${ }^{5}$. Goals for the primary and secondary prevention of coronary artery disease were established. The goals for secondary prevention were reinforced by the findings of the CARE trial ${ }^{6}$.

Although the recommendations about the control of risk factors for coronary artery disease are a constant among international medical societies ${ }^{7,8}$, studies show low adherence to those recommendations from patients and from physicians ${ }^{9,10}$. The most classic example is the data from the EUROASPIRE ${ }^{11}$ study, showing low rates of control of arterial hypertension, a still high proportion of smokers and obesity, besides showing the low use of statins by coronary artery disease patients 6 months after hospitalization. We believe that lack of adherence to those guidelines, which in their majority were validated by clinical evidence, harms patients.

In Brazil little is known about the behavior of physicians regarding coronary artery disease prevention. The purpose of this study was to report, through the use of a general questionnaire and questions based on clinical cases, about the knowledge of a group of Brazilian physicians, most of them cardiologists, regarding the recommendations of the II Brazilian Guidelines Conference on Dyslipidemias 
and the state of the art of primary and secondary prevention measures for coronary atherosclerosis.

\section{Methods}

This was a descriptive cohort study conducted during the LIV Congress of the Brazilian Society of Cardiology in the city of Recife in September 1999. Seven hundred and forty-six physicians, $20 \%$ of the congress' attendees, $98 \%$ cardiologists, were evaluated. Forty percent of the participants were from the north/northeast regions, $37 \%$ were from the southwest regions, $13 \%$ were from the south, and $10 \%$ were from the west central region.

Both the questionnaire and the clinical cases were prepared by members of the Departments of Atherosclerosis and Clinical Cardiology of the Brazilian Society of Cardiology, aided by professionals experienced in market research. The questions addressed mainly the importance given by physicians to dyslipidemia and whether they know the recommendations of the II Brazilian Guidelines Conference on Dyslipidemias. In summary those recommendations were: total cholesterol and LDL-C, respectively, $<200 \mathrm{mg} / \mathrm{dL}$ and $<100 \mathrm{mg} / \mathrm{dL}$ in secondary prevention and $<240 \mathrm{mg} / \mathrm{dL}$ and $<130 \mathrm{mg} / \mathrm{dL}$ in high-risk primary prevention ( 2 or more risk factors besides elevated cholesterol). In low-risk primary prevention (less than 2 risk factors besides elevated cholesterol) the recommendations were LDL-C $<160 \mathrm{mg} / \mathrm{dL}$ but $>130 \mathrm{mg} / \mathrm{dL}$. In all cases triglyceride levels $<200 \mathrm{mg} / \mathrm{dL}$ and HDL-C $>35 \mathrm{mg} / \mathrm{dL}$ were recommended. A special recommendation was made for diabetics, because they show a very high risk of coronary events. Similar values were suggested for secondary prevention patients, but in this case triglycerides should be $<150 \mathrm{mg} / \mathrm{dL}$.

Assessment procedure-1) Specific questions - Each participant in the Congress was given, together with the material related to the Congress, a questionnaire to be filled individually containing 11 questions. The questions were to be answered anywhere, without hurrying, and upon completion placed in urns distributed around the convention center during the Congress.

See Appendix 1 for the full text of these questions.

1) Estimate the proportion of coronary artery disease patients seen by physicians in their offices.

2) Evaluate the proportion of patients diagnosed as having dyslipidemia.

3) Estimate the percentage of the lipid disturbances found in the patients' (4 options).

4) Behavior physicians recommended before a patient was diagnosed with dyslipidemia: diet only; drug therapy only; a diet-and-drug therapy, and no treatment at all.

5) Experience in managing hyperlipidemias.

6) Evaluate the knowledge of the recommendations proposed by the II Brazilian Guidelines Conference on Dyslipidemias in 6 clinical situations

7) Answers to statements regarding dyslipidemia treatment in which participants would agree or not.

8) The importance attributed by the physician to treatment interruption, using a predefined scale.
9) The time necessary for a new evaluation of plasma lipids after the treatment was started.

10) Average duration of the drug treatment for dyslipidemia.

11) Which drugs physicians believed to be able to change the natural history of coronary disease in coronary artery disease patients, with or without previous infarct.

2) Clinical cases - Four clinical cases were proposed to assess the knowledge of each physician regarding the recommendations of the II Brazilian Guidelines Conference on Dyslipidemias, as well as the current literature, in the following clinical situations: a patient with coronary artery disease, but with no hypercholesterolemia; a patient with secondary dyslipidemia; a patient with diabetes mellitus and hypertriglyceridemia; a patient in primary prevention at high risk for coronary artery disease. Physicians were asked to answer the questions by female monitors distributed through the Congress. Cases were presented on data sheets to be evaluated by the physicians on a separate sheet. The assessment of the results of the clinical cases will be the object of separate papers to be published, which will discuss the results in depth.

\section{Results}

In question $1,39 \%$ of the physicians said that $10-25 \%$ of their patients had coronary artery disease. In question 2 , $47 \%$ of the physicians said that $25-50 \%$ of the patients had lipid disorders. Among the reported lipid changes, the most frequent was mixed dyslipidemia $31 \%$, followed by isolated hypercholesterolemia $30 \%$; hypertriglyceridemia $21 \%$, and the isolated decrease of HDL-C $18 \%$. In the treatment of dyslipidemia, $39 \%$ of the physicians said they would use diet only, $8 \%$ would use drugs only, $49 \%$ would use a combination of diet and drugs, and $4 \%$ would not treat the patients. Fifty-seven percent of the physicians answered that, on the average, their patients took from 2 to 4 months to reduce or normalize their cholesterol. The answers given to questions 6 and 7 are in tables I and II, respectively. When asked in question 8 about the importance that some factors might have regarding the discontinuation of drugs, the most valued items were: change of patient's habits (7.5), followed by patient awareness (7.3), and by concomitant pathologies (7.0). The type of drug used was considered the least important factor (5.3). The intermediate position was occupied by cost (6.5), side effects (6.2), the treatment, and the amount of drug (5.5). In question 9, almost $95 \%$ of participants answered that he or she would ask for a new lipid profile during the first 6 months following the start of the treatment. The answers given to question 10 about the duration of the dyslipidemia treatment are shown in table III. When stimulated in question 11 to mention which drugs they believed would change the natural history of coronary artery disease, statins were the most mentioned $75.1 \%$, followed by antiplatelet drugs $45 \%$, beta-blockers $42.3 \%$, ACE inhibitors $25.3 \%$, fibrates $9.7 \%$, thrombolytic drugs $4.7 \%$, calcium antagonists $2.5 \%$, nitrates $2.2 \%$, other drugs $3.2 \%$, and no answer $2.3 \%$. 


\begin{tabular}{|c|c|c|c|c|c|c|c|c|c|c|c|c|c|}
\hline & & \multicolumn{2}{|c|}{$\begin{array}{c}\text { Man, } \\
40 \text { years, } \\
\text { hypertensive } \\
\text { diabetic }\end{array}$} & \multicolumn{2}{|c|}{$\begin{array}{c}\text { Woman } \\
40 \text { years, } \\
\text { non smoker, } \\
\text { normotensive } \\
\text { normoglycemic }\end{array}$} & \multicolumn{2}{|c|}{$\begin{array}{l}\text { Mam, } \\
50 \text { years, } \\
\text { smoker, } \\
\text { CAD }\end{array}$} & \multicolumn{2}{|c|}{$\begin{array}{c}\text { Woman, } \\
40 \text { years } \\
\text { type II diabetes }\end{array}$} & \multicolumn{2}{|c|}{$\begin{array}{c}\text { Woman, } \\
38 \text { years, } \\
\text { smoker } \\
\text { dyslipidemia } \\
\text { mixed }\end{array}$} & \multicolumn{2}{|c|}{$\begin{array}{l}\text { Man, } 45 \text { years, } \\
\text { smoker father } \\
\text { (52 yr old) brother } \\
\text { (48 yr old), } \\
\text { both infarcted }\end{array}$} \\
\hline & & $\mathrm{N}$ & $\%$ & $\mathrm{~N}$ & $\%$ & $\mathrm{~N}$ & $\%$ & $\mathrm{~N}$ & $\%$ & $\mathrm{~N}$ & $\%$ & $\mathrm{~N}$ & $\%$ \\
\hline \multirow[t]{4}{*}{$\mathrm{TC}$} & $<200$ & 676 & 90.6 & 531 & 71,2 & 686 & 92.0 & 644 & 86.3 & 636 & 85.3 & 608 & 81.5 \\
\hline & 201 a 239 & 18 & 2.4 & 84 & 11,3 & 9 & 1.2 & 28 & 3.7 & 25 & 3.4 & 82 & 11.0 \\
\hline & $>240$ & 21 & 2.8 & 98 & 13.1 & 19 & 2.5 & 31 & 4.2 & 46 & 6.2 & 23 & 3.1 \\
\hline & N. A. & 31 & 4.2 & 33 & 4.4 & 32 & 4.3 & 43 & 5.8 & 39 & 5.2 & 33 & 4.4 \\
\hline \multirow[t]{5}{*}{ LDL-C } & $<100$ & 195 & 26.1 & 35 & 4.7 & 416 & 55.8 & 184 & 24.7 & 118 & 15.8 & 287 & 38.5 \\
\hline & 101 a 130 & 416 & 55.8 & 360 & 48.3 & 229 & 30.7 & 410 & 55.0 & 465 & 62.3 & 354 & 47.5 \\
\hline & 131 a 159 & 50 & 6.7 & 96 & 12.9 & 33 & 4.4 & 45 & 6.0 & 53 & 7.1 & 23 & 3.1 \\
\hline & $>160$ & 45 & 6.0 & 212 & 28.4 & 23 & 3.1 & 54 & 7.2 & 64 & 8.6 & 36 & 4.8 \\
\hline & N. A. & 40 & 5.4 & 43 & 5.8 & 45 & 6.0 & 53 & 7.1 & 46 & 6.2 & 46 & 6.2 \\
\hline \multirow[t]{4}{*}{ HDL-C } & $<35$ & 266 & 35.7 & 254 & 34.0 & 230 & 30.8 & 228 & 30.6 & 227 & 30.4 & 239 & 2.0 \\
\hline & $36-51$ & 289 & 38.7 & 313 & 42.0 & 305 & 40.9 & 310 & 41.6 & 318 & 42.6 & 294 & 39.4 \\
\hline & $>52$ & 153 & 20.5 & 143 & 19.2 & 176 & 23.6 & 164 & 22.0 & 166 & 22.2 & 179 & 24.0 \\
\hline & NR & 38 & 5.1 & 36 & 4.8 & 35 & 4.7 & 43 & 5.8 & 36 & 4.8 & 34 & 4.6 \\
\hline \multirow[t]{3}{*}{ TG } & $<200$ & 630 & 84.4 & 627 & 84.0 & 621 & 83.2 & 601 & 80.6 & 616 & 82.6 & 614 & 82.3 \\
\hline & $>201$ & 25 & 3.4 & 31 & 4.2 & 16 & 2.1 & 25 & 3.3 & 32 & 4.3 & 17 & 2.3 \\
\hline & NR & 91 & 12.2 & 88 & 11.8 & 110 & 4.7 & 120 & 16.1 & 98 & 13.1 & 115 & 15.4 \\
\hline
\end{tabular}

\section{Discussion}

The study population had knowledge of the role and treatment of dyslipidemia in the prevention of atherosclerosis. The great majority of participants said they believed that the treatment of dyslipidemia prevents atherosclerosis, and statins were said by participants to be the main drugs that change the natural history of atherosclerosis, well above the anti-platelet drugs and beta-blockers. However, we have found distortions in the knowledge of the recommendations of the II Brazilian Guidelines Conference on Dyslipidemias and on the use of hypolipemic drugs.

The combination of pharmacological treatment and diet was the favorite option for the control of dyslipidemia. However, although they recognized the value of statins, almost $40 \%$ of participants would treat their patients with a diet only. In our opinion, this approach is valid in cases of low-risk primary prevention, but not in cases of secondary prevention. The base of any hypolipemic treatment is diet. However, evidence exists that the reduction of LDL-C with Phase I and Phase II diets in individuals who are out of metabolic units is about $6 \%{ }^{12}$. In cases of secondary prevention, a diet would hardly reduce LDL-C to $25-30 \%$, nor would the target of LDL-C $<100 \mathrm{mg} / \mathrm{dL}$ be reached. Values attained would depend on the dose or type of statin used ${ }^{2,13}$.

Total cholesterol levels $<200 \mathrm{mg} / \mathrm{dL}$ were recommended by most of the participants for the hypothetical patients in question 6, even for the 38-year-old female without any other risk factor besides high cholesterol. In general, when total cholesterol is $<200 \mathrm{mg} / \mathrm{dL}$, LDL-C is about $100 \mathrm{mg} / \mathrm{dL}$, except in the case of patients with low HDL-C levels. The total cholesterol value may be a substitute for LDL-C, as long as the HDL-C is also measured. Data from Framingham ${ }^{1}$ in- dicate that the total cholesterol/HDL-C ratio is a predictor of risk of coronary artery disease. Also, in the $4 \mathrm{~S}$ study ${ }^{3}$ the treatment target was to reduce total cholesterol to levels $<200 \mathrm{mg} / \mathrm{dL}$. Our study's finding would be stimulating if the values found for LDL-C followed the values of total cholesterol. In patients with coronary artery disease and in those with diabetes mellitus, an undesirably high number of physicians considered levels of LDL-C $<100 \mathrm{mg} / \mathrm{dL}$ as appropriate. In the other cases of primary prevention, it seems that many physicians accepted the recommendations of the consensus conference. However, another common mistake among participants was that almost one third of the responders considered levels of HDL-C $<35 \mathrm{mg} / \mathrm{dL}$ as desirable, when for all situations those levels should be $>35 \mathrm{mg} / \mathrm{dL}^{5}$. The great majority of responders followed the guidelines conference recommendations regarding triglyceride levels.

Although a large number of participants agreed on the use of hypolipemic drugs to prevent CAD, between $35 \%$ and $60 \%$ of the participants said they would not maintain such drugs after reaching the levels recommended for prevention. In question 10, a great number of the participants chose not to answer about the duration of the treatment, and only about one third of all participants said they would keep the pharmacological therapy indefinitely. This fact is worrisome because the participants did not take into account the evidence that the difference in the clinical benefit from using statins will differ from that of using placebo only after 1 to 2 years of continuous treatment ${ }^{2}$. The average treatment duration in the large statin studies was 5.4 years. After statins are discontinued, lipids will probably return to their pretreatment values and, until proven otherwise, the pharmacological treatment must be continued indefinitely.

Another fact that worries us is that only $35 \%$ of the 


\begin{tabular}{|c|c|c|c|c|c|c|c|c|c|c|}
\hline \multicolumn{11}{|c|}{ Table II - Answers given by the 746 participants to question 7} \\
\hline & \multicolumn{2}{|c|}{$\begin{array}{c}\text { Totally } \\
\text { agree }\end{array}$} & \multicolumn{2}{|c|}{$\begin{array}{l}\text { Partially } \\
\text { disagree }\end{array}$} & \multicolumn{2}{|c|}{$\begin{array}{l}\text { Partially } \\
\text { agree }\end{array}$} & \multicolumn{2}{|c|}{$\begin{array}{l}\text { Totally } \\
\text { disagree }\end{array}$} & \multicolumn{2}{|c|}{$\begin{array}{l}\text { Did not } \\
\text { answer }\end{array}$} \\
\hline & $\mathrm{N}$ & $\%$ & $\mathrm{~N}$ & $\%$ & $\mathrm{~N}$ & $\%$ & $\mathrm{~N}$ & $\%$ & $\mathrm{~N}$ & $\%$ \\
\hline $\begin{array}{l}\text { A very small portion of my patients } \\
\text { fill drug prescriptions. }\end{array}$ & 84 & 11.3 & 239 & 32.0 & 184 & 24.7 & 230 & 30.8 & 9 & 1.2 \\
\hline $\begin{array}{l}\text { I believe that keeping lipid levels under control by } \\
\text { means of chronic treatment is beneficial to the patient. }\end{array}$ & 619 & 83.0 & 78 & 10.5 & 18 & 2.4 & 14 & 1.9 & 17 & 2.3 \\
\hline A very small portion of patients follow diets. & 216 & 29.0 & 341 & 45.7 & 128 & 17.2 & 44 & 5.9 & 17 & 2.3 \\
\hline $\begin{array}{l}\text { I believe that drug treatment of dyslipidemia } \\
\text { should be maintained indefinitely. } \\
\text { Once the required lipid levels are attained, }\end{array}$ & 338 & 45.3 & 229 & 30.7 & 102 & 13.7 & 63 & 8.4 & 14 & 1.9 \\
\hline I maintain the prescription of the drug that is being used. & 304 & 40.8 & 289 & 38.7 & 88 & 11.8 & 52 & 17.0 & 13 & 1.7 \\
\hline $\begin{array}{l}\text { The clinical objective is to prevent cardiovascular events } \\
\text { from occurring. I treat dyslipidemia in order to prevent }\end{array}$ & 563 & 75.5 & 127 & 17.0 & 30 & 4.0 & 14 & 1.9 & 12 & 1.6 \\
\hline $\begin{array}{l}\text { lipid levels, I change the medication. } \\
\text { Once the lipid levels are attained, }\end{array}$ & 219 & 29.4 & 367 & 49.2 & 111 & 14.9 & 37 & 5.0 & 12 & 1.6 \\
\hline I reduce the drug dosage. & 185 & 24.8 & 298 & 39.9 & 111 & 14.9 & 135 & 18.1 & 17 & 2.3 \\
\hline $\begin{array}{l}\text { I insist and try to change the lifestyle of my patients } \\
\text { with risk factors for coronary artery disease. }\end{array}$ & 686 & 92.0 & 32 & 4.3 & 5 & 0.7 & 11 & 1.5 & 12 & 1.6 \\
\hline $\begin{array}{l}\text { Once the required lipid levels are attained, I change the } \\
\text { medication for another of the same category, but less powerful. } \\
\text { I believe that the treatment of lipid disorders does }\end{array}$ & 42 & 5.6 & 101 & 13.5 & 96 & 12.9 & 495 & 66.4 & 12 & 1.6 \\
\hline $\begin{array}{l}\text { change the natural history of coronary disease. } \\
\text { I treat hypercholesterolemia with drugs only when }\end{array}$ & 647 & 86.7 & 68 & 9.1 & 10 & 1.3 & 8 & 1.1 & 13 & 1.7 \\
\hline $\begin{array}{l}\text { the patient has total cholesterol above } 320 \mathrm{mg} / \mathrm{dL} \text {. } \\
\text { When the drug treatment does not reach the required }\end{array}$ & 27 & 3.6 & 60 & 8.0 & 79 & 10.6 & 567 & 76.0 & 13 & 1.7 \\
\hline lipid levels, I increase the dosage of the same drug. & 265 & 35.5 & 379 & 50.8 & 65 & 8.7 & 25 & 3.4 & 12 & 1.6 \\
\hline $\begin{array}{l}\text { Once the required lipid levels are attained, I must } \\
\text { discontinue the drug therapy and maintain a diet. }\end{array}$ & 95 & 12.7 & 211 & 28.3 & 171 & 22.9 & 258 & 34.6 & 11 & 1.5 \\
\hline
\end{tabular}

\begin{tabular}{|lcc|}
\hline \multicolumn{2}{|c|}{ Table III - Average time of dyslipidemia treatment according to } \\
the 746 participants \\
\hline Time of treatment & N & $\%$ \\
\hline less than 1 month & 2 & 0,3 \\
from 1 to 3 months & 40 & 5,3 \\
from 3 to 6 months & 66 & 9,0 \\
from 6 to 9 months & 17 & 2,3 \\
from 9 months to 1 year & 22 & 2,9 \\
more than 1 year & 53 & 7,2 \\
whole life & 245 & 33,0 \\
did not answer & 301 & 40,0 \\
Total & 746 & 100 \\
\hline
\end{tabular}

participants said they would increase the doses, and 18\% said they would change the drug in order to reach the levels recommended by the consensus conference. This finding suggests a lack of knowledge of the pharmacology of statins and the prevention studies. In case the recommended value is not reached or, as an alternative, reductions between 25 and 35\% in LDL-C occur, as happened in the clinical studies $^{2}$, the dose must be increased ${ }^{3,14}$ or the drug may be changed to a more powerful one ${ }^{15}$. Each time we double the dose of statins, an average $6 \%$ reduction occurs in LDL-C ${ }^{16}$. None of the large studies on prevention used any dosage of statins that might be considered low. On the contrary, the $4 \mathrm{~S}^{3}$ study used 20-40 mg of simvastatin; the WOSCOPS ${ }^{4}, \mathrm{CARE}^{6}$ and LIPID ${ }^{17}$ studies used $40 \mathrm{mg}$ of pravastatin, and the AFCAPS/TEXCAPS ${ }^{14}$ study used $20-40 \mathrm{mg}$ of lovastatin. Those were the minimum required doses to achieve a satis- factory reduction in total cholesterol and LDL-C. One should remember that in the studies performed in the ' 70 s and ' 80 s with fibrates ${ }^{18,19}$ resins $^{20}$, and in the recent HERS ${ }^{21}$ study with estrogens and progestogens, the small $10 \%$ decrease of in total cholesterol was not enough to reduce coronary mortality or coronary events, as was the case in the latter study . Statins are a safe group of drugs for which the incidence of serious side effects is very low, in the order of $0.08 \%$ to $1.5 \%$ for the increase of aminotransferases and $\mathrm{CPK}^{22}$. Higher doses may be used safely ${ }^{15}$.

The change of habits and the awareness of patients, as well as concurrent pathologies, were considered more important than the cost and side effects of the drugs, for the discontinuation of the pharmacological treatment. For the participants, as well as in reports in the literature ${ }^{23,24}$, life style changes are very important and may be the only provision required in cases of primary prevention. But in cases of secondary prevention, we would like to emphasize that statins add to other preventive measures and are not superseded by them ${ }^{25}$. It is possible that chronic concomitant diseases needing continuous treatment have a negative impact on the use of statins due to the high cost of the latter. Also, patients having to take a great number of medications would reduce adherence to the treatment.

Despite the fact that our study might contain biases such as the small sample size, if we take into account Brazil's expanse, that a predominance of physicians came from the congress region, and possible preconceptions of the participants, our results are not different from those of studies 
conducted in other countries. Frolics et al. evaluating colleagues in the United States showed that only $50 \%$ of the physicians evaluated would adopt NCEP goals for LDL-C ${ }^{26}$. Data from the EUROASPIRE ${ }^{11}$ study showed that about $44 \%$ of coronary artery disease patients that were evaluated had cholesterol levels above the recommended values. Recently, another large U.S. study that evaluated 140 cardiology and multispeciality clinics showed that only $25 \%$ of 58,890 patients with coronary disease had reached the target of LDL-C $<100 \mathrm{mg} / \mathrm{dL}$ proposed by the $\mathrm{NCEP}^{27}$. One of the explanations for these findings is that physicians were not in the habit of following the recommendations given by the societies, or maybe they did not know those recommendations ${ }^{10}$. Another explanation might be the excessive number of recommendations or consensus statements about various diseases, which make the job of the physician very hard to perform if he or she were to try to comply with all of them.

In conclusion, in the study population, both the recommendations given during the II Brazilian Guidelines
Conference on Dyslipidemias and the information from the large studies on prevention are not being followed as they should be. Apparently, the participants had little understanding of the use of statins for prevention. These findings could be indicators of what is going on in our country as a whole. In order to correct the distortions found in our study, we propose that the findings of this study and the international studies that evaluated the knowledge of the control of dyslipidemias be divulged. Physicians must also be made aware of the continuing medical education courses organized jointly by the Departments of Atherosclerosis, Clinical Cardiology, and FUNCOR. Also a plan is underway to update the II Brazilian Guidelines Conference on Dyslipidemias with an emphasis on new information and the reinforcement of the recommendations for lipid values, treatment duration, and the assessment of the absolute risk of coronary disease as a threshold value in pharmacological treatment. The next step would be to give courses aimed at the population in general which, in our opinion, is mostly interested in preventing cardiovascular events.

\section{References}

1. Castelli WP. The new pathophysiology of coronary artery disease. Am J Cardiol 1998; 82: 60T-65T.

2. LaRosa JC, He J, Vupputuri S. Effect of statins on risk of coronary disease. A metaanalysis of randomized controlled trials. JAMA 1999; 282: 2340-6.

3. Scandinavian Simvastatin Survival Study Group: Randomized trial of cholesterol lowering in 4444 patients with coronary heart disease: The Scandinavian Simvastatin Survival Study (4S). Lancet 1994; 344: 1383-9.

4. Shepherd J, Cobbe SM, Ford I, et al for The West of Scotland Coronary Prevention Study Group. Prevention of coronary heart disease with pravastatin in men with hypercholesterolemia. N Eng J Med 1995; 333: 1301-07.

5. II Consenso Brasileiro sobre Dislipidemias. Detecção, avaliação e tratamento. Arq Bras Cardiol 1996; 67: 1-16.

6. Sacks FM, Pfeffer MA, Moye LA, etal. The effect of pravastatin on coronary events after myocardial infarction in patients with average cholesterol levels. Cholesterol and Recurrent Events Trial investigators. N Engl J Med 1996; 335: 1001-09.

7. Summary of the second report of the National Cholesterol Education Program (NCEP) Expert Panel and detection, evaluation, and treatment of high blood cholesterol in adults (Adult Treatment Panel II). JAMA 1993; 269: 3015-23.

8. Pyoralla K, De Backer G, Graham I, Poole-Wilson P and Wood D on behalf of the Task Force. Prevention of coronary heart disease in clinical practice. Recommendations of the Task force of the European society of Cardiology, European Atherosclerosis Society, and European Society of Hypertension. Eur Heart J 1994; 110: 121-61.

9. Roberts WC. The underused miracle drugs: The Statin drugs are to atherosclerosis what penicilin was to infectious diseases. Am J Cardiol 1996; 78: 377-8.

10. Feely J. The therapeutic gap-compliance with medication and guidelines. Atherosclerosis 1999; 147(suppl 1): S31-S7.

11. EUROASPIRE Study Group. EUROASPIRE a European Society of Cardiology survey of secondary prevention of coronary heart disease: Principal Results. Eur Heart J 1997; 18: 1569-82.

12. Smith GD, Shah E. Systematic review of dietary intervention trials to lowerblood total cholesterol in free-living subjects. Br Med J 1998; 316: 1213-20.

13. Nawrocki JW, Weiss SR, Davidson MH et al. Reduction of LDL-cholesterol by $25-60 \%$ in patients with primary hypercholesterolemia by atorvastatin, a new $\mathrm{H}$ MGCo-A reductase inhibitor. Arterioscler Thromb Vasc Biol 1995; 15: 678-82.

14. Downs JR, Clearfield M, Weiss DO, et al. Primary prevention of acute coronary events with lovastatin in men and women with average cholesterol levels. Results of AFCAPS/TEXCAPS. JAMA 1998; 279: 1615-22
15. Jones $P$, Kafonek S, Laurora I, Hunninghake D. Comparative dose efficacy study of atorvastatin versus simvastatin, pravastatin, lovastatin, and fluvastatin in patients with hypercholesterolemia. Am J Cardiol 1998; 81: 582-7.

16. Vaughn CJ, Gotto Jr AM, Basson CT. The evolving role of statins in the management of atheroscleroris. J Am Coll Cardiol 2000; 35: 1-10.

17. The Long-Term Intervention with Pravastatin in Ischaemic Disease (LIPID) Study Group. Prevention of Cardiovascular Events and Death with Pravastatin in Patients with Coronary Heart Disease and a Broad Range of Initial Cholesterol Levels. N Engl J Med 1998; 339: 1349-57.

18. Reportfrom the Committee of Principal Investigators. A co-operative trial in the primary prevention of ischaemic heart disease using clofibrate. Br Heart J 1978; 40: 1069-18.

19. Frick MH, Elo O, Haapa K, et al. Helsinki heart study: primary prevention trial with gemfibrozil in middle-aged men with dyslipidemia. N Eng J Med 1987; 317: 1237-45.

20. Lipid Research Clinics Program. The Lipid Research Clinics Coronary Primary Prevention Trial Results. 1. Reduction in incidence of coronary heart disease. JAMA 1984; 214: 351-64.

21. Hulley S, Grady D, Bush T, et al. Randomized trial of estrogen plus progestin for secondary prevention of coronary heart disease in postmenopausal women. Heart and estrogen/progestin replacement study (HERS) research group. JAMA 1998; 280: 605-13.

22. Shepherd J. Fibrates and statins in the treatment of hyperlipidaemia: an appraisal of their efficacy and safety. Eur Heart J 1995; 6: 5-13.

23. Martinez-Gonzalez MA, Bueno-Cavanillas A, Sanchez-Izquierdo F, Aguinaga Ontoso I, Jimenez-Moleon JJ, Delgado-Rodriguez M. Changes in coronary risk profiles in employees after three years of multifactorial intervention. Eur J Epidemiol 1998; 14: 653-62.

24. Grimm RH Jr. The multiple risk factor intervention trial in the U.S. A summary of results at four years in special intervention and usual care men. Prev Med. 1983; 12: $185-90$.

25. Flanagan DE, Cox P, Paine D, Davies J, Armitage M. Secondary prevention of coronary heart disease in primary care: a healthy heart initiative. QJM 1999; 92: 245-50.

26. Froliks JP, Zyzanski SJ, Schwartz JM, Suhan PS. Physician noncompliance with the 1993 National Cholesterol Education Program (NCEP-ATP II) guidelines. Circulation 1998; 98: 851-5.

27. Sueta CA, Chowdhury M, Boccuzzi SJ, et al. Analysis of the degree of undertreatment of hyperlipidemia and congestive heart failure secondary to coronary artery disease. Am J Cardiol 1999; 83: 1303-07. 


\section{Appendix 1 \\ Full questions proposed to physicians.}

SBC questionnaire

\section{SBC text}

1. Of the patients you see in your practice, how many have coronary artery disease?

( ) up to $10 \%$ of patients

( ) from $25 \%$ to $50 \%$ of patients

( ) from $50 \%$ to $75 \%$ of patients
( ) from $10 \%$ to $25 \%$ of patients

( ) more than $75 \%$ of patients

2. Of the patients you see in your practice, how many have diagnosed lipid change?
( ) up to $10 \%$ of patients
( ) from $10 \%$ to $25 \%$ of patients
( ) from $25 \%$ to $50 \%$ of patients

( ) from $50 \%$ to $75 \%$ of patients

( ) more than $75 \%$ of patients

3. Of your patients with diagnosed lipid change, what is the percentage with:
A- High total cholesterol and normal triglycerides
B- High LDL and normal triglycerides
C- High triglycerides and normal cholesterol
D- High LDL and triglycerides

\section{Should add 100}

4. Of your patients with diagnosed lipid change, what is the percentage for the following provisions:
A-Diet only
B-Drug therapy only
C- Diet and drug therapy combined
D- Do not treat

Should add 100

5. On the average, how long (how many months) does it take to reduce or normalize cholesterol by means of drug therapy?

6. What is the required blood level of the following lipid fractions for the following types of hypothetical patients?

\begin{tabular}{|c|c|c|c|c|}
\hline Profile & Total - C & LDL - C & HDL & Triglycerides \\
\hline \multicolumn{5}{|c|}{ Man, 40 years; hypertensive and diabetic } \\
\hline \multicolumn{5}{|c|}{ Woman, 40 years, non smoker, normotensive and normoglycemic } \\
\hline \multicolumn{5}{|c|}{ Man, 50 years, smoker, with Coronary arterial disease } \\
\hline \multicolumn{5}{|l|}{ Woman, 40 years } \\
\hline \multicolumn{5}{|l|}{ Type II diabetes } \\
\hline \multicolumn{5}{|l|}{ Woman, 38 years, smoker, } \\
\hline \multicolumn{5}{|l|}{ mixed dyslipidemia } \\
\hline \multicolumn{5}{|l|}{ Man, 45 years, smoker } \\
\hline Infarcted father ( 52 years) & & & & \\
\hline & & & & \\
\hline
\end{tabular}


7. Regarding the statements below, answer on a scale of 1 to 4 , where:

1 - totally agree

3 - partially disagree
2 - partially agree

4 - totally disagree

\begin{tabular}{|c|c|c|c|c|}
\hline & 1 & 2 & 3 & 4 \\
\hline \multicolumn{5}{|l|}{ A very small portion of my patients fills drug prescriptions. } \\
\hline \multicolumn{5}{|l|}{ I believe that maintaining lipidic levels under control by means of chronic treatment is beneficial to the patient. } \\
\hline \multicolumn{5}{|l|}{ A very small portion of patients follow diets. } \\
\hline \multicolumn{5}{|l|}{ I believe that drug treatment of dyslipidemia should be maintained indefinitely. } \\
\hline \multicolumn{5}{|l|}{ Once the required lipid levels are reached, I maintain the prescription of the drug that is being used. } \\
\hline \multicolumn{5}{|l|}{ The clinical objective is to prevent cardiovascular events from occurring. I treat dyslipidemia in order to prevent. } \\
\hline \multicolumn{5}{|l|}{ When the drug treatment does not reach the required lipid levels, I change medication. } \\
\hline \multicolumn{5}{|l|}{ Once the lipid levels are attained, I reduce the drug dosage. } \\
\hline \multicolumn{5}{|l|}{ I insist and try to change the lifestyle of my patients with risk factors for the Coronary Artery Disease. } \\
\hline \multicolumn{5}{|c|}{ Once the required lipid levels are attained, I change the medication to another of the same category, but less powerful. } \\
\hline \multicolumn{5}{|l|}{ I believe that the treatment of lipid disorders does change the natural history of the coronary disease. } \\
\hline \multicolumn{5}{|l|}{ I treat hypercholesterolemia with drugs only when the patient has total cholesterol above $320 \mathrm{mg} / \mathrm{dL}$. } \\
\hline \multicolumn{5}{|l|}{ When the drug treatment does not reach the required lipid levels, I increase the dosage of the same drug.. } \\
\hline Once the required lipid levels are reached, I must discontinue the drug therapy and maintain a diet. & & & & \\
\hline
\end{tabular}

8. For the items below, what is the degree of difficulty to reach the objectives in the treatment of lipid disorders? $(1=$ no difficulty; $8=$ highly difficult)

\begin{tabular}{|l|l|l|l|l|l|l|l|l|}
\hline & $\mathbf{1}$ & $\mathbf{2}$ & $\mathbf{3}$ & $\mathbf{4}$ & $\mathbf{5}$ & $\mathbf{6}$ & $\mathbf{7}$ & $\mathbf{8}$ \\
\hline Side effects & & & & & & & \\
\hline Cost of treatment & & & & & & & \\
\hline Type of drug & & & & & & & & \\
\hline Amount of drug & & & & & & & & \\
\hline Awareness of patient & & & & & & & & \\
\hline Change in patient's habits & & & & & & & & \\
\hline Concomitant pathologies & & & & & & & & \\
\hline
\end{tabular}

9. After how many months of treatment (diet and/or drug), do you ask for a new lipid profile to reassess a patient?
( ) less than 3 months
( ) from 3 to 6 months
( ) from 6 to 9 months

( ) from 9 months to 1 year

( ) more than 1 year

( ) I don't ask

10. What is the average period of drug treatment for dyslipidemias?
( ) less than 1 month
( ) from 1 to 3 months
( ) from 3 to 6 months
( ) from 6 to 9 months

( ) from 9 months to 1 year
( ) more than 1 year
( ) whole life

11. In patients with Coronary Artery Disease, with or without infarct, which drugs do you believe will change the natural history of the disease? 